\title{
Viagens: itinerários de sensibilidade e razão
}

\author{
Travels: routes of sensibility and reason
}

\author{
Cinthia Maria de Sena Abrahão (ABRAHÃO, C. M. S.) * \\ Marcelo Chemin (CHEMIN, M.) ${ }^{* *}$
}

\begin{abstract}
RESUMO - Este artigo traz uma reflexão sobre o ato de viajar e a experiência estética que lhe é inerente. Parte-se da hipótese que a contemporânea massificação das viagens torna ainda mais complexa a experiência do sujeito-viajante. A partir disso, percorre-se por meio de pesquisa bibliográfica, eletrônica e iconográfica, dois momentos da história das viagens: (i) século XVIII, com a rota dos grand tourists, em que viajar era um recurso para a busca de conhecimento e para a formação cultural e estética, porém circunscrito em termos de acesso à elite cultural e econômica; (ii) século XIX, a partir dos registros iconográficos e relatos dos viajantesnaturalistas, que estiveram no continente americano, direcionados pelo interesse de conhecimento científico. Faz-se também, um destaque à passagem dos naturalistas pelo Brasil oitocentista, demonstrando o caráter etnológico contido nestas viagens. Por fim, sugere-se a relevância da dimensão social das viagens contemporâneas, subsidiadas pelo avanço tecnológico e pela ampla viabilização de acesso das experiências de deslocamento espacial.
\end{abstract}

Palavras-chave: Estética; Grand-Tour; Turismo; Viagem; Viajantes-naturalistas

ABSTRACT - This article brings a reflection on the act of travelling and the aesthetic experience that him is inherent. The initial hypothesis is that the massification of contemporary travels makes still the experience of the traveling-subject one more complex. For so much, it is passed through bibliographical, electronic inquiry and iconographic, two moments of the history of the travels: (i) eighteenth century, with the route of the grand tourists, when it travels was a resource for the search of knowledge and for the cultural and aesthetic formation, however his access was circumscribed to the cultural and economical elite; (ii) nineteenth century, with the iconographic registers and reports of the naturalist-traveling ones, which were in the American continent, guided for the scientific knowledge interest. It is still done, a distinction to the passage of the naturalists for Brazil in eighteenth century, demonstrating the ethnological character of these travels. Finally, the dimensions assumed by the act suggest the relevance of thinking of travelling contemporarily, subsidized by the technological advancement and about the mass access of the experiences of space dislocation.

Key words: Esthetics; Grand-tour; Travel; Tourism; Naturalists-travellers

\footnotetext{
Graduação em Ciências Econômicas pela Universidade Federal de Uberlândia (UFU). Mestre em Ciências Humanas pela Universidade de São Paulo (USP) e doutoranda em Geografia pela Universidade Federal do Paraná (UFPR). Professora do curso de Gestão em Turismo da UFPR - Setor Litoral. Endereço: Rua Jaguariaíva, 512. CEP: 83260-000 - Matinhos - PR (Brasil). Telefone: (41) 3511-8300. Email: cisena@terra.com.br.

** Bacharel em Turismo pela Universidade Estadual de Ponta Grossa (UEPG). Mestre em Turismo e Hotelaria pela Universidade do Vale do Itajaí (UNIVALI), doutorando em Geografia pela UFPR. Professor do curso de Gestão em Turismo da UFPR - Setor Litoral. Endereço: Rua Jaguariaíva, 512. CEP: 83.260-000 - Matinhos - PR (Brasil). Telefone: (41) 3511-8300. Email: marcelochemin@ufpr.br.
} 


\section{INTRODUÇÃO}

O intenso fluxo de viagens para os mais diversos lugares constitui algo tão presente no mundo contemporâneo que assume contornos de naturalidade e de rotina. Contudo, nas sociedades humanas é relativamente recente o desenvolvimento de condições efetivas para a consolidação desta prática. Pode-se dizer que até o século XVII, os seres humanos, em sua maioria, mantinham suas vidas circunscritas a alguns poucos quilômetros de distância em relação às suas moradas.

$\mathrm{Na}$ sociedade capitalista, os deslocamentos voluntários assumiram proporção significativa a ponto de constituírem um hábito cultural de especial valor social. A questão tempo com suas subdivisões tornou-se marcante nesta sociedade, sobretudo por dois grandes grupos, o tempo do trabalho e o do não trabalho. Este último, por sua vez, desperta o interesse dos estudiosos das práticas de lazer e turismo.

O tempo do não trabalho possibilita a experimentação do descanso, além de favorecer a cultura do lazer, associada entre outras coisas, ao prazer e à fuga de rotinas, do ritmo de vida conhecido, das certezas corriqueiras. A conquista do tempo de não trabalho é fator profícuo para o avanço das práticas sociais ligadas ao lazer e ao turismo, que se organizaram no seio da sociedade contemporânea por meio de uma rede de serviços e espaços direcionados a dar suporte à dinâmica do fenômeno turístico.

A natureza do deslocamento humano é por si estimuladora de mudanças sociais, via promoção de descobertas e experiências enriquecedoras para a vida cultural de qualquer indivíduo. Historicamente, a análise de estudos e registros do século XVIII na Europa, possibilita demonstrar que uma viagem roteirizada já anunciava a atividade turística. O Grand Tour ${ }^{1}$ tornou-se praticamente uma exigência à formação dos filhos das famílias abastadas, aristocráticas e burguesas (SALGUEIRO, 2002, p. 291). No entanto, a realização desta modalidade de viagem não contava com as disponibilidades de prestação de serviços e infra-estrutura tal qual a organização vigente do turismo.

O turismo nos moldes contemporâneos articula-se em função de certa organização das comunidades humanas que relaciona configurações sociais e culturais a contextos econômicos e políticos, cuja dinâmica favorece a realização de viagens. Para isso, tempo livre, meios de transportes, comunicação, serviços de apoio constituem

\footnotetext{
${ }^{1} \mathrm{O}$ grand tour constituiu-se talvez como um primeiro itinerário de viagem definido com o fim exclusivo do conhecimento de outros lugares. Em geral, incluía a França, Suíça, Alemanha e, em especial, a Itália.
} 
elementos de base. Com efeito, da comunicação que age sobre a motivação para a realização das viagens, passando pela infra-estrutura e equipamentos necessários ao deslocamento, formação de profissionais adequados às especialidades de cada área de apoio, até a ordenação das acomodações e lugares, identifica-se um conjunto de atividades que compõem o turismo e expressam uma parcela da economia mundial de significativa importância.

$\mathrm{Na}$ medida em que se torna um setor relevante para a economia, em termos de geração de riqueza, impõe-se a padronização de processos e sistemas de controle de produção dos próprios serviços turísticos. Os princípios da produção fordista ${ }^{2}$, que possibilitam padronização na indústria de bens de consumo em geral, bem como instrumentalizaram o controle de qualidade, tornaram-se imperativos para as atividades turísticas, tais como o foram para outros setores da economia. Estes princípios combinam elementos básicos da racionalização do processo produtivo, envolvendo redução de gastos e melhor utilização dos recursos.

De que forma este processo de padronização influenciou e influi na prática turística? Quais os reflexos destas padronizações nas experiências humanas de viagem?

Questões como estas conduzem à exploração do significado da viagem em si, tema este que pode constituir um flanco a ser desvelado. Importante frisar que o exercício argumentativo contido neste texto não pretende parametrizar ou estabelecer uma hierarquia para os significados das viagens, mas instigar sobre o seu conhecimento social e intimista.

A reflexão do antropólogo Marc Augé sobre o 'sistema-mundo' é uma das plataformas possíveis para se analisar as viagens enquanto fenômeno social contemporâneo. Augé (1994, p. 31-36) vê um mundo de excessos: excesso de tempo, de espaço e de ego. A 'aceleração' da história, sentida a partir da explosão e simultaneidade de fatos faz experimentar uma densidade factual que "ameaça suprimir todo e qualquer significado" (p. 31). A partir disso este pesquisador aponta a existência da crise do significado, pois a sociedade em pequenos intervalos de tempo tem acesso permanente a vários fatos. Isto, porém, resulta que os indivíduos não conseguem avançar na compreensão destes fatos. Contribui para este quadro social de crise, os usos estabelecidos a partir da noção de espaço que chega aos indivíduos apenas pela

\footnotetext{
${ }^{2} \mathrm{O}$ termo fordista está vinculado ao modelo baseado na produção em massa de bens industrializados, que representou o ponto alto da ruptura com o modo artesanal de produção.
} 
percepção visual, em geral manipulada por imagens (publicidade, ficção, informação) que brincam com a fantasia, as escalas, perspectivas e outros referenciais.

Como o significado de uma viagem poderia ser interpretado no mundo descrito por Augé?

Uma hipótese instigadora seria a que considera o fator programático e a gestão eficaz das viagens como elementos influentes sobre a experiência cultural por elas proporcionada. A surpresa propiciada pelo contato com realidades diferentes do habitual pode ser indicada como exemplo decorrente desta experiência cultural.

Neste sentido, o viajante contemporâneo participa de um sistema onde a semelhança dos roteiros de viagens, dos meios de deslocamento, de hospedagem e de alimentação pode se transformar num simplificador do significado da experiência turística no que diz respeito ao elemento surpresa, à novidade, ao que pode ser diferente do cotidiano. Desdobramento deste quadro poderá ser a novidade sendo "coisificada", transformada em intermediária daquilo que nasce como objetivo, o conhecer outros lugares e outras pessoas em práticas contra-rotineiras.

A influência da padronização sobre a experiência turística em termos da percepção individual do viajante é algo ainda insuficientemente explorado. Apesar disso, é importante destacar que são disponibilizadas experiências turísticas diversificadas e de distintos graus de intensidade. Isto implica dizer que a experiência turística demonstra o elemento incontrolável inerente a uma atividade que proporciona o contato de pessoas com lugares, pessoas e coisas. Os resultados produzidos a partir daí não são passíveis de serem completamente previstos por mais extensa que seja a padronização alcançada. Ao mesmo tempo, pode-se dizer que os contatos gerados neste processo são potencialmente transformadores em diversos sentidos, tanto do viajante, como com o que ou quem ele se relaciona.

Neste artigo encontra-se uma análise a respeito de elementos que estão presentes na história das viagens e do turismo. Sua contribuição está no destaque atribuído à dimensão subjetiva do fenômeno contemporâneo das viagens, pouco valorizada em estudos e pesquisas da área. Constitui base de análise a reflexão da viagem como experiência estética e de conhecimento. Interpretou-se em dois momentos da história moderna como se realizaram as práticas de viagem. O primeiro compreende o século XVIII, através dos grand tourists. O segundo momento corresponde ao século XIX, 
especificamente as viagens científicas realizadas para a América espanhola e portuguesa.

\section{APONTAMENTOS SOBRE A VIAGEM COMO EXPERIÊNCIA ESTÉTICA}

Explorar a qualidade experiencial da viagem como prática social e cultural em contraponto às práticas de organização ou até mesmo superorganização das viagens constitui uma rica oportunidade de investigação epistemológica, em que os recursos da semiótica, das representações sociais e da fenomenologia são opções proficientes.

Investigar este tema envolve analisar a satisfação do sujeito-viajante e verificar a viagem em sua potencialidade enriquecedora da vida humana. É descobrir e estudar a experiência em si e não seus resultados, por isso não basta a historicidade das viagens ou ainda um recorte desta historicidade, mas avançar rumo a uma hermenêutica das viagens.

Em meio à amplitude da proposta parece oportuno destacar um pilar desta temática, ou seja, analisar a viagem como experiência estética. Isto conduz a esforços de interpretação dos sentidos da viagem para o sujeito, em sua condição e temporalidade de viajante. É ir além das motivações, um dos assuntos do campo turístico que valoriza aspectos intimistas, e por isso, enxergar o sujeito contido na figura do turista.

Especial contribuição é a de Jonh Urry (2001) que escreveu sobre o olhar do turista. No conjunto, os olhares dos turistas são lançados fora dos ambientes de rotina, eles se constroem em relação ao seu oposto, ou seja, a partir das formas não turísticas de experiência e consciência social. Este pesquisador aponta que as viagens e o turismo, ligados ao lazer, férias e prazer, possuem suas práticas e experimentação vinculadas a lugares diferentes do cotidiano, possíveis a partir de uma ruptura programática e limitada de ambiente e rotina. Ao viajar o turista suspende temporariamente suas obrigações e fora de seu ambiente pode vivenciar outro ritmo de vida, contrastante com o ritmo 'rotineiro', o que constitui uma experiência rica em seus sentidos.

As fantasias e devaneios desempenham um importante papel na escolha e na programação de uma viagem, pois de acordo com Urry (2001), associam-se a expectativas construídas em hábitos não turísticos e por meios diversos de obtenção das 
informações. Deve-se ressaltar que a expectativa e o olhar em relação ao lugar visitado se constroem por meio de signos, geralmente associados ao lazer e prazer.

As satisfações resultantes da experiência e do consumo turístico não se limitam, por esta abordagem, à seleção, aquisição e uso de produtos. Urry (2001, p. 29-30) entende que a satisfação nasce da expectativa e da procura do prazer, situados na imaginação. O consumo não é simplesmente material, pois as pessoas procuram "vivenciar, "na realidade' os dramas agradáveis que já vivenciaram em sua imaginação" (p. 23).

O ato de viajar como experiência humana é portador de sentido social e cultural. Social porque ativamente envolve valores e funções socialmente estabelecidos para as viagens. Cultural porque reconhece as viagens como práticas simbólicas e de significação humana.

Refletir sobre o turismo enquanto ato semiótico, considerando a abordagem de Sahr e Löwen Sahr (2001), por exemplo, reforça a compreensão do turismo enquanto fenômeno social e cultural. Estes pesquisadores entendem que ao mesmo tempo em que o turismo corresponde a uma espécie de fome insaciável de dramatizações nos imaginários sociais de pessoas que buscam um relaxamento de rotinas e do cotidiano, a prática do turismo também apela às necessidades existenciais da vida social, com seu suspense, excitação e possibilidades de identificação lúdica e divertimento contemplativo.

O processo perceptivo é tema importante para a reflexão das viagens enquanto experiências estéticas. A percepção está presente cotidianamente nas relações de mediação entre homem e ambiente (DEL RIO, 1990; LYNCH, 1997) e desempenha papel preponderante nas práticas de viagem, pois como processo permite ao sujeito avaliar a experiência das viagens. Isto ocorre devido a operação dos sentidos humanos que captam estímulos por meio da visão, audição, tato, olfato e gustação. Quando levados ao cotidiano e também à experiência de viagem, estes sentidos promovem uma trama de respostas e sensações aos indivíduos. Apesar do sentido da visão exercer papel supostamente dominante na percepção humana, as viagens compõem-se por experiências que envolvem sabores, cheiros, sons e contatos diversos.

Del Rio (1990, p. 92) ao comentar a percepção do meio ambiente, afirma que o homem se comunica através de um processo cognitivo, que é a construção do sentido 
mentalmente objetivado. Como processo, está direcionado a ação e memorização, onde conta com três etapas principais: percepção (campo sensorial); seleção (campo da memória) e atribuição de significado (campo do raciocínio). $\mathrm{O}$ ato de viajar enquanto experiência estética está, por conseguinte, relacionado às condições destes três campos, na medida em que a "percepção é, acima de tudo, um processo seletivo, pois nós só percebemos aquilo que nossos objetivos mentais nos preparam para perceber" (p. 92).

Estética é vocábulo que deriva do grego aisthesis, cujo significado está vinculado a noção do que é sensível ou daquilo que se relaciona com a sensibilidade. Envolve por conta disso, percepção, impressões, sentimentos, razão e deleite (NUNES, 1989, p. 12).

A raiz grega da palavra é aisth, do verbo aisthonomai, ou sentir - este sentir não é relacionado ao 'coração' ou sentimentos, mas sim com os sentidos, numa noção de rede de percepções físicas (SANTAELLA, 1994, p. 11). Coelho Netto (2007, p. 165) explica que a etimologia de estética também se relaciona com aisthanesthai, que significa 'compreensão' pelos sentidos e aistheticos - que tem faculdade de sentir.

De acordo com Nunes (1989, p. 12-15), a estética foi fundada como disciplina por Alexander Gottlieb Baumgarten e posteriormente consolidada por Emmanuel Kant, cuja obra 'Crítica do juízo' trouxe contribuições ao seu estudo. A partir da proposição kantiana a questão do belo converteu-se teoricamente em 'experiência estética'. Nunes (1989) compreende que de modo geral, a experiência estética pode ser investigada em dois aspectos: subjetivo e objetivo. O subjetivo é relativo ao sujeito que sente e julga. $\mathrm{O}$ objetivo voltado aos objetos que condicionam ou provocam sentimento e julgamento.

Outro ponto a referenciar é que a compreensão das viagens, enquanto conjunto de experiências estéticas se sustenta historicamente. Vale lembrar que as viagens foram importantes recursos de aprendizagem e aperfeiçoamento cultural. A respeito disso e destacando o papel da paisagem como recurso pedagógico, Meneses (2002) escreveu sobre a historicidade do olhar e os usos da paisagem. Partiu, naturalmente, da premissa de que a estrutura perceptiva é histórica e relatou como na Inglaterra do século XVIII as formas de olhar diferenciavam socialmente os indivíduos, de forma que a aristocracia parametrizava "bom gosto" a partir do culto ao pitoresco - previamente estruturado, acessível por meio da arte e de viagens. Estes códigos estéticos, que eram 
parametrizados nesta época, integram códigos históricos que estão em transformação contínua na sociedade e nos indivíduos.

Oportuno dizer que as viagens de cientistas e naturalistas expressaram o debate em torno da natureza do conhecimento nos séculos XVIII e XIX (KURY, 2001). Conforme Ferreira e Simões (1986, s. p.), Kant classificou em duas as formas de 'conhecer', a experiência, pela via do conhecimento empírico, e o raciocínio. O embate entre a razão dedutiva ou indutiva, idealismo ou empirismo acompanharam a história da modernidade. Parte dos pensadores que sustentam o pensamento moderno se afiliam à idéia de que a razão e a dedução lógica são suficientes para gerar respostas a grande parte das dúvidas humanas. Outra parte elenca a experiência, a empiria, enquanto chave do conhecimento.

Neste sentido, Nunes (1989) indica que para Kant há três modalidades de experiência: a cognoscitiva (conhecimento intelectual), que é vinculada a conceitos, pelos quais se formam as idéias das coisas e se estabelecem relações; a prática, que é relativa aos fins morais que se busca atingir na vida, e por fim, a estética, "fundamentada na intuição ou no sentimento dos objetos que nos satisfazem, independente da natureza real que possuem. Essa satisfação começa e termina com os objetos que a provocam" (p. 13).

Considerando a análise sobre viagens e estética aqui realizada, é possível afirmar que o ato de viajar pode ser compreendido enquanto experiência estética e, portanto, promotor de conhecimento. Com efeito, a viagem mostra-se uma vivência sócioespacial de profundo valor cultural ligado ao lazer e, como qualquer vivência, está submetida aos elementos que caracterizam o tempo vivido, a ser experimentado pelos indivíduos.

\section{NOVOS VELHOS SENTIDOS PARA O ATO DE VIAJAR: DO GRAND TOUR Às EXPEDIÇÕES CIENTÍFICAS}

As transformações vividas pelas sociedades ocidentais nos últimos séculos que caracterizam a consolidação da modernidade capitalista trouxeram à tona uma série de novos hábitos e valores. Há que se destacar o valor da liberdade, inerente à cultura humanista. A esta se liga de forma inexorável a liberdade de ir e vir, que por sua vez 
está relacionada ao direito adquirido modernamente de deslocar-se voluntariamente. (CARNEIRO, 2001).

A partir dos séculos XIV, XV e XVI, o homem passou a se perceber como criador mediante a natureza (Lara, 1986). Ao mesmo tempo em que se libertava da admiração, adoração, obediência frente ao ambiente natural, passava a cultivar novos valores relacionados à individualidade, liberdade, criatividade, participação e enriquecimento.

Racional e livre se professava o homem moderno. Homem pronto para inventar e criar. O palco de suas atividades era a imensidão dos espaços e do tempo, e a medida do seu progresso era infinita. Acreditava-se na história como marcha certeira para um futuro glorioso (LARA, 1986, p. 73).

A revolução industrial inglesa representou a força da ciência colocada a serviço da vida prática e da compreensão dos mecanismos naturais, permitindo a dessacralização da vida e da natureza. Possibilitou, assim, uma transformação impressionante na capacidade de organizar o mundo material.

Engajado a este processo, o desenvolvimento dos meios de transporte e de comunicação tornaram-se a própria expressão da modernidade, época em que a redução do tempo necessário para a realização de qualquer atividade tornou-se uma obsessão. Foi em meio à profusão de acontecimentos do século XIX que a natureza foi assumida de forma mais prática e contundente enquanto objeto de pesquisa e ação transformadora.

O deslocamento espacial de um volume cada vez maior de pessoas foi se tornando realizável e conferindo concretude ao ir e vir. Conforme Carneiro (2001), na Europa medieval, as peregrinações estavam entre as poucas motivações para que as pessoas deixassem seu local de morada. O sedentarismo e o apego ao lugar compuseram a essência ideológica e, por conseguinte, de controle social do feudalismo (p. 230).

O deslocamento voluntário, como fonte de prazer e conhecimento, foi retomado a partir do período marcado pelo Iluminismo clássico, quando houve uma busca incessante por elementos presentes nas civilizações da Antiguidade clássica. (SALGUEIRO, 2002, p. 291). Neste período, a sabedoria estava vinculada ao conhecimento de muitos povos e lugares.

Os primeiros fluxos significativos de viagens direcionadas ao puro prazer foram registrados na Europa setecentista (SALGUEIRO, 2002). Estas viagens, em busca de 
deleite e emoção, estavam vinculadas ao objetivo de aprimoramento pessoal através de valores estéticos. As descobertas científicas e a ruptura com a filosofia escolástica traziam à tona uma nova onda de descobertas, de compreensão do homem em sua trajetória histórica. O chamado grand tour possibilitava aos viajantes que vissem com seus próprios olhos, que vivenciassem lugares que tinham as marcas do passado revelado pela história moderna (p. 292-294).

Não por acaso este fenômeno coincidiu com a primeira etapa de consolidação do capitalismo. Embora ainda fossem precárias as condições para o deslocamento e para a realização das viagens, havia um novo olhar e a revalorização do conhecimento, que se destacavam como características da sociedade burguesa emergente (SALGUEIRO, 2002). Isto explicita porque grande parte dos viajantes do século XVIII era proveniente da Inglaterra, berço do capitalismo europeu. Segundo Salgueiro (2002, p. 291), no século XVIII todo inglês de posses passou a ter incluso em sua formação um tour continental.

No percurso que ficou conhecido como grand tour havia um roteiro completo que incluía viagem à Paris e um circuito pelas cidades italianas, Roma, Veneza, Florença e Nápoles (SALGUEIRO, 2002). De forma mais ou menos intensa, o grand tourist era obrigado a conviver com as diferenças, encontrava-se mediante paisagens naturais e humanas distintas daquelas de onde provinha.

A escrita do diário e a ilustração faziam parte de um ritual metodológico que ia se impondo, cujo ponto alto era a sua publicação ao retorno do viajante, o que ampliava o conhecimento e despertava o interesse dos leitores para novos projetos de viagem e novos conhecimentos (SALGUEIRO, 2002, p. 301).

O grand tourist trouxe à tona as características do 'turista universal', no sentido apontado por Nery (2003, p. 10-12), sujeito dotado de autonomia, aberto a novas experiências, fluído, em busca do novo. Dentre os diversos nomes que são importantes para a reconstrução deste fenômeno da viagem relacionada à descoberta e a autodescoberta, o poeta Goethe é considerado uma espécie de representante exemplar do viajante que tratou a experiência da viagem como algo significativamente diferente da vida cotidiana. Neste sentido, transcende ao deslocamento físico, consiste também no deslocamento moral (NERY, 2003). 
A arte era essencial na cultura da viagem, tanto pela contemplação, como pela produção (Salgueiro, 2002). Na medida em que o espírito da viagem exigia mais do que a percepção visual, pois buscava uma experiência cognitiva, o conhecer e o apreender, estimulava pari passu uma relação original com o lugar. Seguindo o preceito do romantismo alemão ${ }^{3}$, que se transformou em um marco de resistência à separação entre razão e emoção, Goethe viajou permanentemente acompanhado por pintores (p. 296).

Deve-se ponderar que a viagem no período tratado até aqui era uma atividade de caráter elitista e restritiva no que tange ao acesso à experiência estética. No primeiro momento, pode-se dizer que a atividade turística teria nascido como uma espécie de 'especiaria', um produto de acesso exclusivo às elites do mundo europeu em processo de transição. Ao tempo em que expandem o horizonte cultural, restringem o acesso às camadas privilegiadas da sociedade. Caráter diverso viria a ser característico da contemporaneidade, na medida em que o acesso ao deslocamento tornar-se-ia acessível a uma gama cada vez maior de pessoas de todas as origens e posições sociais.

Ao longo do século XIX, quando se consolidou o processo de transição para o capitalismo na Europa a partir da Revolução Industrial, o fluxo de viagens alterou suas dimensões (PRATT, 1991). Isto ocorreu não apenas em função da infra-estrutura que o desenvolvimento das forças produtivas proporcionou, mas também dos novos contornos sócio-econômicos e os ativos culturais vinculados a interesses dos homens para deslocamentos por meio de viagens.

Também no século XIX, os impérios europeus adentravam uma nova etapa da expansão colonialista, o que teve início no século XVI (PRATT, 1991, p. 2). As porções litorâneas do "novo mundo" já haviam sido cartografadas, restava então, avançar para o interior dos continentes americano e africano. Os cientistas viajantes foram responsáveis por esta saga que permitiu expandir o conhecimento sobre os territórios explorados e as novas fronteiras dos continentes.

A expansão colonialista desde o século XVI, que fez surgir um "novo" mundo, foi também responsável pela provocação de outros olhares e, com isto, novos desafios ao conhecimento e à ciência. Ainda assim, por muito tempo o continente americano

\footnotetext{
${ }^{3}$ O romantismo representou uma corrente filosófica importante do Século XIX. Em sua corrente alemã, em especial a reação ao racionalismo, destacou-se através da busca de uma linguagem do conhecimento que mantivesse unidas as duas formas perceptivas importantes para a busca do conhecimento, a científica baseada na razão e artística baseada na sensibilidade (GOMES, 2005).
} 
permaneceu fechado às descobertas e às reflexões das ciências em geral, inclusive das ciências naturais (PRATT, 1991). Em geral, a ação das Coroas colonialistas foi insensível ao conhecimento efetivo da realidade encontrada nos trópicos (DEAN, 1996, p. 135).

Tratando da história da devastação da floresta Atlântica no Brasil, Dean (1996) desmitifica a relação do homem com a floresta, ambiente desde sempre inóspito para o humano. A relação de antagonismo acompanha as sociedades humanas, o que torna evidente que os colonizadores não encontraram intacta a natureza deste continente americano. Imbuídos do interesse mercantil de exploração e inebriados pela crença na abundância de espécies naturais, apenas muito tardiamente este espaço tornar-se-ia palco de interesse e de disponibilidade de estudos e pesquisas. A ignorância e o desperdício caminharam lado a lado ao longo do processo de dominação territorial conhecido como colonização do "novo" mundo.

Na etapa de consolidação da ciência moderna, entre os séculos XVIII e XIX, os cientistas renovaram a visão em relação ao valor das expedições científicas (PRATT, 1991). Segundo Kohlepp (2006, p. 261-262), o cientista Alexander Humboldt ajudou a 'redescobrir' a América a partir de sua viagem à região equinocial ${ }^{4}$ do continente. Obteve a concessão da Coroa espanhola para o estudo minucioso de vastas regiões da América Central e do Sul, o que ocorreu entre 1799 e 1804. Sua entrada no território de domínio português, no entanto, foi vetada.

A partir deste empreendimento, capitaneado por Humboldt, desencadeou-se uma série de expedições, organizadas para o novo mundo, cujo intuito não era o de usufruir exclusivamente de novas experiências estéticas. Contudo, a percepção destes indivíduos tornou-se marcadamente distinta a partir destas vivências, revelando o elemento culturalmente transformador inerente à viagem.

No caso da América portuguesa, apenas a partir de 1808 com a transferência da família real portuguesa para o Brasil, foragida das tropas de Napoleão Bonaparte, tiveram início as primeiras expedições científicas. Conforme Dean (1996, p. 141), esta foi uma das primeiras decorrências da abertura dos portos às nações estrangeiras.

\footnotetext{
${ }^{4}$ Humboldt era cientista naturalista, seus trabalhos contribuíram para a fundamentação científica de diversas áreas das ciências naturais e humanas, em especial para a Geografia. A região equinocial do continente americano corresponde aos territórios atuais dos seguintes países, Venezuela, Cuba, Colômbia, Equador, Peru e México (KOHLHEPP, 2006).
} 
Entre os viajantes que estiveram no Brasil, ao longo do século XIX, destacam-se os naturalistas Johan Baptist von Spix e Carl Friedrich von Martius, Wilhelm L. Eschwege, Auguste Saint-Hilaire, o príncipe Maximiliano von Wied-Neuwied, o barão Langsdorff, cônsul da Rússia, os pintores Jean-Baptiste Debret, Johan Moritz Rugendas, Thomas Ender e os ingleses John Luccock, Maria Graham e John Mawe (DEAN, 1996).

Em grande parte, tais expedições foram compostas por cientistas e artistas, sendo que alguns desses se tornaram independentes no objetivo de retratação da realidade vivenciada. De acordo com Dean (1996), a profusão de cores, o calor, a diversidade étnica, enfim tudo questionava a métrica, a forma neoclássica da pintura do século XIX Este desafio também se apresentava como referência para a compreensão dos contornos assumidos por este "novo" mundo.

Embora um artista possa retratar com precisão esta ou aquela flor no solo da floresta, a floresta inteira desafia a habilidade artística. Nenhuma pintura ou foto - que não passam de meras obras - consegue captar a presença envolvente, misteriosa, da floresta, sua "solidez plástica" (DEAN, 1996, p. 142).

Segundo Carneiro (2001), no período que precedeu ao século XIX, durante domínio holandês no nordeste brasileiro, o trabalho científico e o artístico foram estimulados de forma articulada. O mesmo autor destaca a vinda de Jorge Marcgrave (1610-1644), responsável por fundar um observatório astronômico em Recife (p. 234). As pesquisas de Marcgrave assumiram intenso caráter geográfico e cartográfico, seguindo seu objetivo de inventariar o domínio natural do território. Para Camargo (2002, p. 83), a descrição etnográfica seguia objetivo claro, no sentido de elucidar o entrosamento e a obediência ao fator geográfico nas práticas e na distribuição da população.

Conforme Camargo (2002, p. 86), no final do século XVIII, Martinho de Melo e Castro, responsável por substituir o Marquês de Pombal no cargo de Primeiro Ministro do Reinado, também enviou expedição científica ao Brasil com o intuito de estudar as riquezas naturais, clima e núcleos de povoamento. Dirigida por um brasileiro, Alexandre Rodrigues de Almeida, naturalista baiano, esta expedição gerou um acervo bastante rico. Este, por sua vez, foi instalado em Lisboa, mas terminou sendo capturado pelos franceses após a invasão de Portugal pelas tropas napoleônicas. 
É compreensível, no entanto, que de forma mais contínua e consistente, os estudos científicos realizados no Brasil a partir da transferência da Corte tenham se tornado mais expressivos. Nesta etapa, interessa destacar a obra dos naturalistas que estiveram em solo brasileiro e desenvolveram seus trabalhos a partir da concepção romântica, que havia marcado o trabalho de Humboldt na América. Este cientista foi responsável por romper com a visão segundo a qual a América representava uma paisagem inferior em relação à européia (CARNEIRO, 2001, p. 238).

Conforme Kury (2001, p. 865-867) deve-se salientar que a atuação dos viajantes naturalistas era a expressão de uma vertente científica que defendia a necessária fusão entre a pesquisa metódica associada à percepção, à tradução sensível da realidade. Os viajantes que deram continuidade à linha de trabalho de Humboldt, na prática, consideravam que a experiência estética compunha a atividade científica. O gosto e a sensibilidade integravam o processo de construção do conhecimento, o que não significava prescindir dos instrumentais técnico-científicos e da precisão que a ciência moderna já propugnava 5 .

É importante que se diga que as obras artísticas ao serem incorporadas no corpo de trabalho das expedições passaram a cumprir uma função, qual seja a de viabilizar a expressão do fenômeno natural sob outra matriz que não apenas a predominante, a escrita. Isto vale tanto para a expressão pictórica, como para a poética.

Ferreira (2004) argumenta que algumas expedições contaram com pintores especialmente contratados para a função de traduzir os fenômenos e a realidade sóciocultural dos locais visitados. Ainda segundo este autor, a expedição organizada pelo barão Georg H. Von Langsdorff foi um destes casos. Iniciada em 1821, com duração de 8 anos, esta expedição partiu do Rio de Janeiro, atravessou o centro do Brasil até a Amazônia, tendo sido uma das mais audaciosas experiências em termos de expedição científica na região até então (p. 235).

Através da experiência proporcionada pela viagem, cientista e artista viam-se confrontados com uma realidade tanto diversa, como complexa. Assim, o "novo" mundo foi perdendo paulatinamente o caráter de "outro" mundo, tornando-se através da

\footnotetext{
${ }^{5}$ Baseado na filosofia de Kant, o romantismo alemão depositava na arte a capacidade de levar o cientista ao alcance daquilo que a razão, por meio da filosofia, não tornaria possível. Neste sentido, o artista proporcionaria o que os filósofos não seriam capazes de proporcionar em termos de apreensão da realidade.
} 
viagem um elemento de transformação da percepção humana. Ilustrando esta condição, Siqueira (2006) analisa a obra do pintor Rugendas (litografia de 1827, "Rua Direita"), para quem a cidade do Rio de Janeiro era tão difícil de representar quanto a paisagem tropical, ambas marcadas pela heterogeneidade.

Neste sentido, pode-se dizer que a história das viagens é capaz de revelar o potencial transformador do deslocamento. Os cientistas viajantes que objetivavam produzir ciência, no seu sentido moderno, adotaram uma via que os levou à expansão da compreensão da realidade pesquisada. Neste sentido, se aproximam dos viajantes que percorreram a rota do grand tour, como requisito essencial da expansão do conhecimento e do status de sua realização. Isto apenas foi possível em função do deslocamento, da visitação in loco, da experimentação e do confronto com situações inusitadas.

\section{CONSIDERAÇÕES FINAIS}

Os dois momentos que serviram de esteio para a análise contida neste artigo, os deslocamentos de viagens produzidos pelo grand tour, no século XVIII, na Europa e, no século XIX, as viagens científicas para a América podem despertar o leitor para dois aspectos inerentes à organização das viagens. Se de um lado, o 'grand tour' revela a busca de conhecer a história a partir da vivência pessoal dos espaços, de outro, vê-se nas expedições científicas, o guia da razão, a busca do conhecimento também através da vivência pessoal, fora do ambiente de controle representado pelos laboratórios. Alternadamente, os componentes da razão e da sensibilidade são explicitados nos diversos itinerários.

A viagem contemporânea, por sua vez, marcada pelas possibilidades que o avanço tecnológico propiciou, em suas múltiplas dimensões e efeitos, configura o ato social e cultural da viagem como campo de expressão da complexidade inerente à percepção humana. Observe-se, por exemplo, a perspectiva de Henrique Soares Carneiro (2001, p. 229), na qual a viagem é algo que se realiza pelos lugares e pelas pessoas, para conhecer gente no espírito e no corpo.

Contemporaneamente, o hábito da viagem assume novos contornos, em função do maior acesso das pessoas às viagens, grande parte delas guiadas pelo objetivo do 
usufruto do lazer. Deriva daí que a atividade turística represente um subsistema econômico cada vez mais importante no contexto da economia global.

Ao mesmo tempo em que ocorre uma necessária organização e padronização do sistema turístico vinculado ao ato do deslocamento voluntário, também se propicia, através das novas tecnologias formas multidimensionais de experimentação e vivência dos lugares. Além disso, o sistema de comunicação permite contatos dos indivíduos viajantes com outros espaços na forma virtual e física.

Pode-se dizer, assim, que a abordagem aqui delineada conduz à reflexão da viagem como experiência estética. Esta, por sua vez, pode encontrar na padronização das atividades de suporte ao turismo uma força de aproximação com as práticas do cotidiano. Isto porque a necessidade de organização cada vez mais intensa das atividades de roteirização e hospedagem, por exemplo, acarretam modelos que se repetem em busca do alcance da qualidade e da própria gestão de custos do negócio.

Desta forma, poderia se pensar que o significado da experiência da viagem, enquanto fuga da rotina e vivência de experiência inusitada pudesse, no limite, deixar de existir. Contudo, o que se percebe é que contemporaneamente o turismo oportuniza a viagem para uma gama antes impensável dos habitantes do planeta. Quanto aos efeitos subjetivos que os deslocamentos provocam, por sua vez, é ainda muito difícil delineálos com clareza.

$\mathrm{O}$ que se pode apontar, no entanto, é que as transformações relacionadas às viagens estão ao alcance de um conjunto maior de pessoas. Acerca dos efeitos desencadeados a partir deste processo e que rebatimentos poderão provocar nas relações humanas, no entanto, é ainda um campo profícuo para uma gama diversa de reflexões e proposições.

\section{REFERÊNCIAS}

AUGÉ, M. Não-lugares: introdução a uma antropologia da supermodernidade. Campinas: Papirus, 1994.

CAMARGO, J. C. G. A Contribuição dos cronistas coloniais e missionários para o conhecimento do território brasileiro. In: Revista de Geografia da UFC, Fortaleza, n. 2, 2002, p. 79-90. 
CARNEIRO, H. S. O Múltiplo Imaginário das viagens modernas: ciência, literatura e turismo. In: História: Questões \& Debates, Curitiba, n. 35, 2001, p. 227-247.

COELHO NETTO, J. T. Semiótica, informação e comunicação. São Paulo: Perspectiva, 2007.

DEAN, W. A ferro e fogo: a história e a devastação da Mata Atlântica brasileira. Trad. Cid Knipel Moreira. São Paulo: Companhia das Letras, 1996.

DEL RIO, V. Introdução ao desenho urbano no processo de planejamento. São Paulo: Pini, 1990.

FERREIRA, C. C.; SIMÕES, N. N. A evolução do pensamento geográfico. Lisboa: Gradiva, 1986.

FERREIRA, R. S. Henry Water Bates: um viajante naturalista na Amazônia e o processo de transferência da informação. In: Revista Ciência da Informação, v. 33, n. 2, 2004, p. 231-240. Disponível em: < http.www.ibict.br/cionline/viewarticle.php? $\mathrm{id}=129$ \&layout=html $>$. Acesso em: 01/04/2008.

GOMES, P. C. C. Geografia e modernidade. Rio de Janeiro: Bertrand Brasil, 2005.

LARA, T. A. Caminhos da Razão no Ocidente - A filosofia ocidental do Renascimento aos nossos dias. Rio de Janeiro: Vozes. 1986.

LYNCH, K. A imagem da cidade. São Paulo: Martin Fontes, 1997.

KOHLEPP, G. Descobertas Científicas da Expedição de Alexander Von Humboldt na América Espanhola (1799-1804) sob o ponto de vista geográfico. In: Revista de Biologia e Ciências da Terra, v. 6, n. 1, 2006, p. 260-278.

KURY, L. Viajantes-naturalistas no Brasil oitocentista: experiência, relato e imagem. In: Revista História-Ciência, Saúde, Manguinhos, v. VIII (suplemento), 2001.

MENESES, U. T. B. A paisagem como fato cultural. In: YÁZIGI, E. (Org.) Turismo e paisagem. São Paulo: Contexto, 2002, p. 29-64.

NERY, P. R. A. Relatos de Viagem e construção da pessoa em Guimarães Rosa - o deslocamento como valor. In: Série Antropologia 331, Brasília, 2003. Disponível em: <www.unb.br/ics/dan/série331empdf.pdf>. Acesso em: 01/05/2008.

NUNES, B. Introdução à filosofia da arte. 5. ed. São Paulo: Ática, 1989.

PRATT, M. L. Humboldt e a Reinvenção da América. In: Estudos Históricos, Rio de Janeiro, v. 4. n. 8, 1991, p. 151-165. 
SAHR, W.; LÖWEN SAHR, C. L. A imagem turística cultural do planalto dos Campos Gerais. In: DITZEL, C. H. M.; LÖWEN SAHR, C. L. (Orgs.) Espaço e cultura: Ponta Grossa e os Campos Gerais. Ponta Grossa: UEPG, 2001, p. 393-414.

SALGUEIRO, V. Grand Tour: uma contribuição à história do viajar por prazer e por amor à cultura. In: Revista Brasileira de História, São Paulo, v. 22, n. 44, 2002, p. 289-310.

SANTAELLA, L. Estética: de Platão a Peirce. São Paulo, 1994.

SIQUEIRA, V. B. Redescobrir o Rio de Janeiro. In: 19\&20. A revista eletrônica de dezenove vinte, v. I, n. 3, 2006. Disponível em: <http://www.dezenovevinte.net>. Acesso em: 13/04/2008.

URRY, J. O olhar do turista: lazer e viagens nas sociedades contemporâneas. 3. ed. São Paulo: Nobel, 2001.

Recebido em: 19/07/2009

Aprovado em: 19/08/2009 